\title{
Multi-response optimization of process parameters using Taguchi method and grey relational analysis during turning AA 7075/SiC composite in dry and spray cooling environments
}

\author{
P. C. Mishra*, D. K. Das, M. Ukamanal, B. C. Routara and A. K. Sahoo
}

School of Mechanical Engineering, KIIT University, Bhubaneswar - 751024, Odisha, India

\begin{tabular}{l}
\hline C H R O N I C L E \\
\hline Article history: \\
Received April 222015 \\
Received in Revised Format \\
May 102015 \\
Accepted June 122015 \\
Available online \\
June 172015 \\
\hline Keywords: \\
Aluminum matrix composite \\
Turning \\
Taguchi method \\
Grey relational analysis
\end{tabular}

\section{Introduction}

Silicon carbide (SiC) reinforced aluminum matrix composites (AMC) are significant for their high strength-to-weight ratio, superior tribological properties, high thermal stability and good corrosion resistance behavior, for which they are increasingly being used in automobile, marine and aerospace industries (Kumar et al., 2010; Suryanarayanan et al., 2013; Das et al., 2014). However, these are difficult-to-machine materials due to the presence of very hard ceramic reinforcements, which also leads to their poor machinability involving high tool wear and surface imperfections (Schubert \& Nestler, 2011; Radhika et al., 2014). During turning AMCs, the integrity of machined surface is affected by particle fracture, interfacial de-lamination, particle pull out and matrix work-hardening (Hung et al., 1995). Gallab and Skald (1998) observed the presence of grooves and holes in the scanning electron micrographs of machined surfaces, due to pull out of SiC particles and fractured SiC particles, during dry high-speed turning of $\mathrm{Al} / \mathrm{SiC}$ composites using poly crystalline diamond (PCD) inserts. Manna and Bhattacharyya (2002) while dry machining SiC reinforced Al 2080 matrix composites using some special

* Corresponding author. Tel: +91 6746540805

E-mail: pcmmech@yahoo.co.in (P. C. Mishra)

(c) 2015 Growing Science Ltd. All rights reserved. doi: $10.5267 /$ j.jijiec.2015.6.002 
tooling systems, observed the average surface roughness reduced with increasing cutting speed; however, that increased with increasing feed and depth of cut. Ciftci et al. (2004) during dry turning of Al 2014/SiC composites, reported that uncoated carbide tools produce better surface finish than coated carbide tools at lower cutting speeds, but Kilickap et al. (2005) observed better surface finish with TiN coated tools than that of uncoated tools, while machining $99.9 \%$ pure $\mathrm{Al} / \mathrm{SiC}$ composites.

Use of coolant during turning increases abrasion between the tool flank and machined surface that leads to groove wear and deteriorates the surface quality (Ding et al., 2005). Surface quality deteriorates during wet turning of ceramic reinforced AMCs, due to flushing away of the partially de-bonded particles thus by creating voids and pit holes on the machined surface (Kannan \& Kishawy, 2006; Kannan \& Kishawy, 2008). Krishna and Reddy (2012) observed an increase in cutting temperature with the increase of either depth of cut or cutting speed, during turning AA 6061/SiC composite using K20 carbide insert. Chandrasekaran and Tamang (2014), while turning SiC reinforced AMCs using PCD inserts reported that feed rate was the most influencing parameter for average surface roughness and material removal rate. Lin (2004) adopted Taguchi method and grey relational analysis (GRA) to optimize cutting parameters for multi-response characteristics (tool life, cutting force and surface roughness) simultaneously, during turning S45C steel using P20 tungsten carbide insert and reported that cutting speed of $135 \mathrm{~m} / \mathrm{min}$, feed rate of $0.08 \mathrm{~mm} / \mathrm{rev}$ and depth of cut of $0.6 \mathrm{~mm}$ were the optimal combination of cutting parameters for the multi-response characteristics. GRA based on Taguchi method was also adopted by Tzeng et al. (2009) to optimize the machining parameters for multiple surface quality targets (i.e. roughness average, roughness maximum and the roundness) simultaneously, during turning SKD 11 (a high carbon, high chromium alloy tool steel) using TiN coated carbide insert and reported that cutting speed of $155 \mathrm{~m} / \mathrm{min}$, feed rate of $0.12 \mathrm{~mm} / \mathrm{rev}$, depth of cut of $0.8 \mathrm{~mm}$ and cutting fluid ratio of $12 \%$ was the optimal combination of machining parameters for the multiple performance characteristics. Sreenivasulu and Rao (2012) applied Taguchi method and GRA to optimize drilling parameters for surface roughness and roundness error simultaneously. Gupta and Kumar (2013) also applied Taguchi method and GRA to optimize turning parameters for surface roughness and material removal rate simultaneously, during turning unidirectional glass fiber reinforced plastic composites; and observed that the depth of cut was the most influencing factor for surface roughness and material removal rate, followed by feed rate.

Krishnamurthy and Venkatesh (2013) in their work presented that during machining, attention should be focused on economy and product quality simultaneously. Surface quality of the product, cutting temperature and material removal rate are the most important factors which influence directly on the machining economy and product quality. Surface roughness is an important index of machinability that determines product quality. Products for precision works require a high degree of surface finish, especially to improve the tribological properties, fatigue strength and corrosion resistance. Machining of a material involves severe plastic deformation in primary and secondary deformation zones, due to which heat is generated and cutting temperature rises. The rise in cutting temperature leads to early wear of cutting tool and the dimensional inaccuracy of the finished product (Krishna \& Reddy, 2012). Moreover; high material removal rate is desirable during machining to increase productivity. Use of coolant during machining the aluminum matrix composites reduces cutting temperature; however, the surface quality is deteriorated as compared to dry machining (Ding et al., 2005; Kannan \& Kishawy, 2006; Kannan \& Kishawy, 2008). In this experiment, a novel method of air-water spray cooling (SC) system has been developed for cooling the work-tool interface zone during turning a SiC reinforced AMC.

This paper presents a comparative study for the multiple quality response characteristics, i.e. average surface roughness (Ra), cutting tool temperature $(\mathrm{T})$ and material removal rate (MRR), while turning the composite both in dry and SC environment for the same machining parameters. In addition to this, it includes a systematic way of optimization of machining process parameters for Ra, $T$ and MRR considered simultaneously, using Taguchi method and GRA during turning the composite bar in both dry and SC environment. 


\section{Materials and methods}

AA 7075 matrix composite reinforced with 20 wt. \% SiC (of average particle size $8.18 \mu \mathrm{m}$ ) was used as work material for turning. Chemical composition test result of the matrix alloy is shown in Table 1 . The composite was fabricated by conventional stir casting method in an electrical resistance furnace, mounted with a speed regulated stirring system and temperature controller.

Table 1

Chemical composition test result of AA 7075

\begin{tabular}{ccccccccccc}
\hline Element & $\mathrm{Si}$ & $\mathrm{Fe}$ & $\mathrm{Cu}$ & $\mathrm{Mn}$ & $\mathrm{Mg}$ & $\mathrm{Zn}$ & $\mathrm{Ti}$ & $\mathrm{Cr}$ & $\mathrm{Al}$ & Others \\
\hline Weight $\%$ & 0.143 & 0.313 & 1.39 & 0.137 & 2.46 & 5.60 & 0.044 & 0.198 & 88.9 & Rest \\
\hline
\end{tabular}

The matrix alloy was heated up to $820^{\circ} \mathrm{C}$ in a steel crucible and then a vortex was created on the surface of the molten alloy by stirring at a speed of $160 \mathrm{rpm}$. The $\mathrm{SiC}$ particles, preheated to $900^{\circ} \mathrm{C}$ for 2 hours, were then added in to the vortex of the molten alloy. The stirring was continued for 10 minutes at a speed of $220 \mathrm{rpm}$. Stirring blades were placed at about one third of the height of the molten metal from its bottom. Before pouring in to a steel mold, about 10 grams of solid Hexachloroethane tablet was dipped into the bottom of the composite slurry for degassing. The pouring temperature of the slurry was around $800^{\circ} \mathrm{C}$. Hardness of the fabricated composite bar was $82 \mathrm{HRB}$. Distribution of reinforced particles in the matrix phase was observed through a Lieca make DMI3000 M inverted optical microscope. Figure 1 represents the optical micrograph of the composite sample at $100 \mathrm{X}$ magnification, which depicts a uniform distribution of SiC particles in the matrix phase, with local agglomeration at some places. The red circular marks in the micrograph indicate the regions of local agglomeration. The composite bar fabricated for turning was of cylindrical shape. Diameter and length of the bar were $50 \mathrm{~mm}$ and $110 \mathrm{~mm}$ respectively. The machining length was $70 \mathrm{~mm}$.

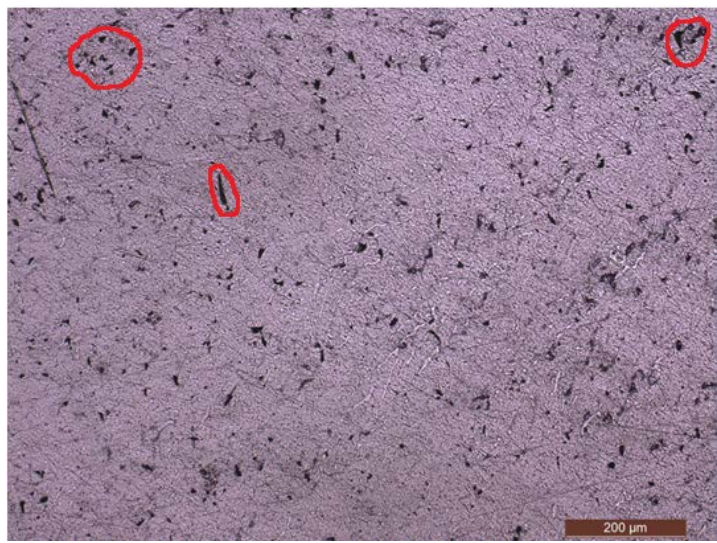

Fig. 1. Optical micrograph of AA 7075/SiC composite sample.

Turning experiments were conducted by a high speed precision lathe (NH 22, HMT) using uncoated carbide inserts of geometry SNMG 120408-THM, manufactured by Kennametal India Ltd. The inserts were clamped rigidly in a turning tool holder of code PSSNR 2525M-12. The experimental setup for generating air-water spray (Fig. 2) consists of an air compressor, a water pump, two pressure regulating valves (one for air and the other for water) and a spray nozzle. Compressed air and water at desired pressure levels are mixed and allowed to pass through the nozzle to produce the spray. Experiments were conducted both in dry and SC machining environments. A constant water pressure of 3 bar and air pressure at four different levels were used for turning the composite in SC environment. 


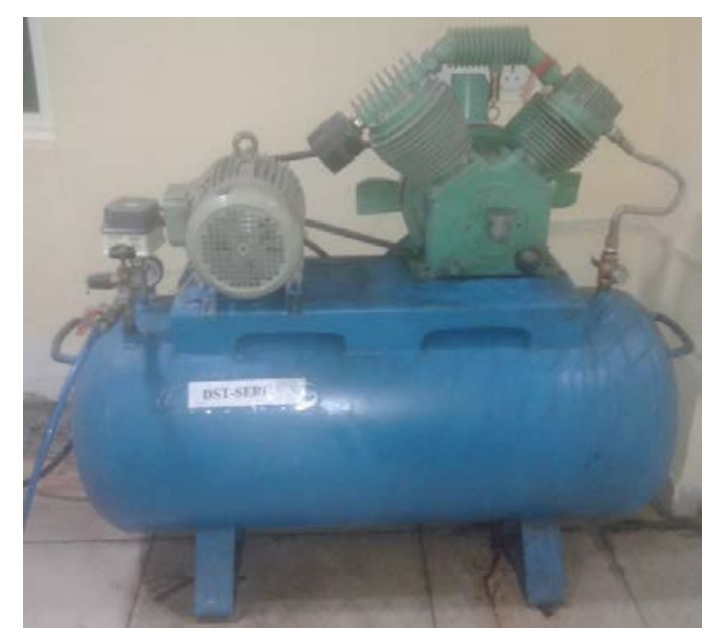

(a)

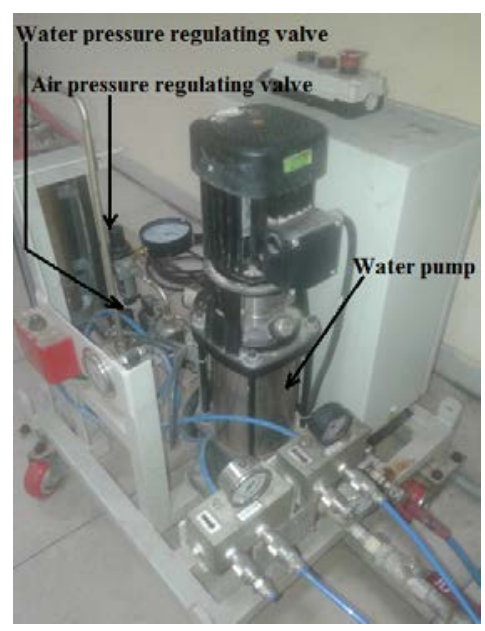

(b)

Fig. 2. Experimental setup for spray generation consisting (a) air compressor; (b) water pump and pressure regulating valves

Fig. 3 and Fig. 4 represent turning setups in dry and SC machining environments respectively. Also, A high-definition infrared thermal imager (FLUKE Ti32) was used to measure $\mathrm{T}$ during turning. Ra of machined surfaces was measured using a surface roughness tester (Taylor Hobson, Surtronic 25), as shown in Fig. 5.

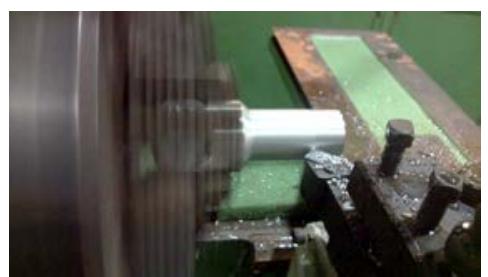

Fig. 3. Turning setup in dry machining environment

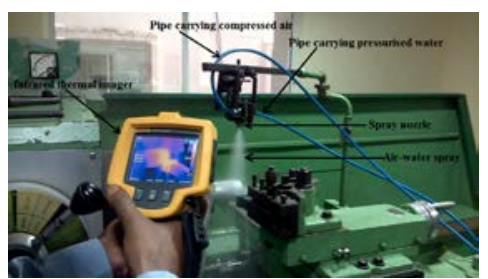

Fig. 4. Turning setup in SC machining environment

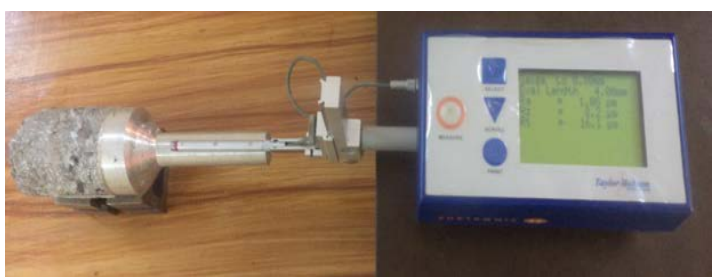

Fig. 5. Surface roughness measurement of machined composite bar

MRR was determined using Eq. (1).

$$
M R R=\frac{\pi}{4}\left(D_{1}^{2}-D_{2}^{2}\right) \cdot f \cdot \frac{N}{60} \mathrm{~mm}^{3} / \mathrm{sec},
$$

where $D_{1}=$ Workpiece diameter before cut $(\mathrm{mm}), D_{2}=$ Workpiece diameter after cut $(\mathrm{mm}), f=$ feed $(\mathrm{mm} / \mathrm{rev})$ and $N=$ Spindle speed of lathe (rpm).

Machining process parameters and their levels used for turning the composite in dry and SC environment are presented in Tables 2 and Table 3, respectively. Experiments were conducted using Taguchi L 16 orthogonal array (Table 4).

\section{Table 2}

Process parameters and their levels for turning in dry environment

\begin{tabular}{ccccccc}
\hline Process & \multirow{2}{*}{ Notation } & \multirow{2}{*}{ Unit } & \multicolumn{4}{c}{ Levels of parameters } \\
\cline { 4 - 7 } parameters & & Level 1 & Level 2 & Level 3 & Level 4 \\
\hline Depth of cut & $\mathrm{d}$ & $\mathrm{mm}$ & 0.2 & 0.4 & 0.6 & 0.8 \\
Feed & $\mathrm{f}$ & $\mathrm{mm} / \mathrm{rev}$ & 0.04 & 0.08 & 0.12 & 0.16 \\
Spindle speed & $\mathrm{N}$ & $\mathrm{rpm}$ & 325 & 420 & 550 & 930 \\
\hline
\end{tabular}


Table 3

Process parameters and their levels for turning in SC environment

\begin{tabular}{|c|c|c|c|c|c|c|}
\hline \multirow{2}{*}{ Process parameters } & \multirow{2}{*}{ Notation } & \multirow{2}{*}{ Unit } & \multicolumn{4}{|c|}{ Levels of parameters } \\
\hline & & & Level 1 & Level 2 & Level 3 & Level 4 \\
\hline Depth of cut & $\mathrm{d}$ & $\mathrm{mm}$ & 0.2 & 0.4 & 0.6 & 0.8 \\
\hline Feed & $\mathrm{f}$ & $\mathrm{mm} / \mathrm{rev}$ & 0.04 & 0.08 & 0.12 & 0.16 \\
\hline Spindle speed & $\mathrm{N}$ & rpm & 325 & 420 & 550 & 930 \\
\hline Air pressure & $\mathrm{Pa}$ & bar & 3 & 2.5 & 2 & 1.5 \\
\hline
\end{tabular}

\section{Table 4}

Taguchi L16 orthogonal array

\begin{tabular}{|c|c|c|c|c|c|c|c|}
\hline \multicolumn{4}{|c|}{ Dry environment } & \multicolumn{4}{|c|}{ SC environment } \\
\hline Run No. & $\mathrm{d}$ & $\mathrm{f}$ & $\mathrm{N}$ & $\mathrm{d}$ & $\mathrm{f}$ & $\mathrm{N}$ & $\mathrm{Pa}$ \\
\hline 1 & 1 & 1 & 1 & 1 & 1 & 1 & 1 \\
\hline 2 & 1 & 2 & 2 & 1 & 2 & 2 & 2 \\
\hline 3 & 1 & 3 & 3 & 1 & 3 & 3 & 3 \\
\hline 4 & 1 & 4 & 4 & 1 & 4 & 4 & 4 \\
\hline 5 & 2 & 1 & 2 & 2 & 1 & 2 & 3 \\
\hline 6 & 2 & 2 & 1 & 2 & 2 & 1 & 4 \\
\hline 7 & 2 & 3 & 4 & 2 & 3 & 4 & 1 \\
\hline 8 & 2 & 4 & 3 & 2 & 4 & 3 & 2 \\
\hline 9 & 3 & 1 & 3 & 3 & 1 & 3 & 4 \\
\hline 10 & 3 & 2 & 4 & 3 & 2 & 4 & 3 \\
\hline 11 & 3 & 3 & 1 & 3 & 3 & 1 & 2 \\
\hline 12 & 3 & 4 & 2 & 3 & 4 & 2 & 1 \\
\hline 13 & 4 & 1 & 4 & 4 & 1 & 4 & 2 \\
\hline 14 & 4 & 2 & 3 & 4 & 2 & 3 & 1 \\
\hline 15 & 4 & 3 & 2 & 4 & 3 & 2 & 4 \\
\hline 16 & 4 & 4 & 1 & 4 & 4 & 1 & 3 \\
\hline
\end{tabular}

\section{Grey relational analysis}

Taguchi method and GRA were used to optimize the machining process parameters for multiple response quality characteristics, i.e. Ra, T and MRR, during turning the composite both in dry and SC environment. GRA can be successfully applied to a system with less or incomplete information. Various steps involved in this method are:

(a) Normalization of experimental results or linear data processing or grey relational generation

(b) Determination of deviation coefficient and grey relational coefficient

(c) Determination of grey relational grades and their order sequencing

(d) Analysis of experimental results using the grey relational grades and statistical ANOVA

(e) Selection of optimal levels of machining parameters

(f) Verification of optimal machining parameters through confirmation experiment

Grey relational generation or linear data processing generates normalized data sequence for the experimental results within 0 and 1 . If the target value of the original sequence is "smaller is better", then the original sequence is normalized as Eq. (2).

$$
x_{i}^{*}(k)=\frac{\max x_{i}^{0}(k)-x_{i}^{0}(k)}{\max x_{i}^{0}(k)-\min x_{i}^{0}(k)} .
$$

However, if the target value is "larger is better", then the original sequence is normalized as Eq. (3).

$$
x_{i}^{*}(k)=\frac{x_{i}^{0}(k)-\min x_{i}^{0}(k)}{\max x_{i}^{0}(k)-\min x_{i}^{0}(k)},
$$


where $x_{i}^{*}(k)$ is the sequence after the data processing or compatibility sequence, $x_{i}^{0}(k)$ is the original sequence of the target value for $i=1,2,3 \ldots ., m$ and $k=1,2, \ldots, n$. $\mathrm{m}$ is total number of experiments and $\mathrm{n}$ is total number of process responses. For the present analysis, $\mathrm{m}=16$ and $\mathrm{n}=3$.

Next step is to determine the deviation coefficient, which is the absolute value of the difference between reference sequence and compatibility sequence, i.e.

$$
\Delta_{0 i}(k)=\left|x_{0}^{*}(k)-x_{i}^{*}(k)\right| \text {, }
$$

where $\Delta_{0 i}(k)$ is deviation coefficient $x_{0}^{*}(k)$ is reference sequence or ideal sequence. Grey relational coefficient is then determined using Eq. (5).

$$
\gamma\left(x_{0}^{*}(k) \cdot x_{i}^{*}(k)\right)=\frac{\Delta_{\min }+\varsigma \cdot \Delta_{\max }}{\Delta_{0 i}(k)+\varsigma \cdot \Delta_{\max }},
$$

where $\gamma\left(x_{0}^{*}(k) \cdot x_{i}^{*}(k)\right)$ is the grey relational coefficient and $\zeta$ is distinguishing coefficient (0 1).

Grey relational grade $\left(\gamma\left(x_{0}^{*} \cdot x_{i}^{*}\right)\right)$ is the weighted sum of the grey relational coefficients and represents the level of correlation between reference and compatibility sequence. It can be calculated using Eq. (6).

$$
\gamma\left(x_{0}^{*} \cdot x_{i}^{*}\right)=\frac{1}{n} \sum_{k=1}^{n} \gamma\left(x_{0}^{*}(k) \cdot \gamma\left(x_{i}^{*}(k)\right)\right) \text {. }
$$

The grey relational grades are than sequenced in descending order. Higher value of grey relational grade represents the stronger relational degree between the reference sequence and compatibility sequence. The highest values of grey relational grade represent the optimal combination of machining parameters for the desired responses (Lin, 2004; Tzeng et al., 2009).

\section{Results and discussion}

\subsection{Multi-response optimization of process parameters}

Table 5 represents the experimental results and normalized data of Ra, $\mathrm{T}$ and MRR during turning in dry environment; and those for turning in SC environment are presented in Table 6. The target values of Ra and T are "smaller is better" and that for MRR is "larger is better".

\section{Table 5}

\begin{tabular}{|c|c|c|c|c|c|c|c|c|c|}
\hline \multirow{2}{*}{ Run no. } & \multicolumn{3}{|c|}{ Machining process parameters } & \multicolumn{3}{|c|}{ Experimental results } & \multicolumn{3}{|c|}{ Normalized data } \\
\hline & $\mathrm{d}$ & $\mathrm{f}$ & $\mathrm{N}$ & $\mathrm{Ra}$ & $\mathrm{T}$ & MRR & $\mathrm{Ra}$ & $\mathrm{T}$ & MRR \\
\hline Ideal sequence & & & & & & & 1 & 1 & 1 \\
\hline 1 & 1 & 1 & 1 & 0.84 & 36.5 & 4.27 & 1.0000 & 1.0000 & 0.0000 \\
\hline 3 & 1 & 3 & 3 & 2.98 & 55.3 & 24.51 & 0.5485 & 0.6649 & 0.2197 \\
\hline 4 & 1 & 4 & 4 & 1.82 & 68.1 & 47.82 & 0.7932 & 0.4367 & 0.4727 \\
\hline 5 & 2 & 1 & 2 & 1.82 & 48.2 & 12.40 & 0.7932 & 0.7914 & 0.0882 \\
\hline 6 & 2 & 2 & 1 & 3.86 & 51.4 & 16.59 & 0.3629 & 0.7344 & 0.1337 \\
\hline 7 & 2 & 3 & 4 & 1.92 & 90.4 & 79.60 & 0.7722 & 0.0392 & 0.8176 \\
\hline 8 & 2 & 4 & 3 & 3.84 & 78.1 & 58.22 & 0.3671 & 0.2585 & 0.5855 \\
\hline 9 & 3 & 1 & 3 & 1.30 & 68.3 & 38.68 & 0.9030 & 0.4332 & 0.3735 \\
\hline 10 & 3 & 2 & 4 & 2.08 & 77.4 & 64.66 & 0.7384 & 0.2709 & 0.6554 \\
\hline 11 & 3 & 3 & 1 & 5.01 & 58.0 & 23.75 & 0.1203 & 0.6168 & 0.2114 \\
\hline 12 & 3 & 4 & 2 & 4.42 & 76.0 & 66.10 & 0.2447 & 0.2959 & 0.6710 \\
\hline 13 & 4 & 1 & 4 & 2.01 & 92.6 & 96.41 & 0.7532 & 0.0000 & 1.0000 \\
\hline 14 & 4 & 2 & 3 & 3.10 & 66.6 & 62.69 & 0.5232 & 0.4635 & 0.6340 \\
\hline 16 & 4 & 4 & 1 & 5.58 & 68.3 & 40.09 & 0.0000 & 0.4332 & 0.3888 \\
\hline
\end{tabular}

Experimental results and data processing of performance characteristics during turning in dry environment 
From the experimental results, it is observed that the values of Ra and T during turning in SC environment are lower than those for dry turning, for the same levels of $\mathrm{d}$, $\mathrm{f}$ and $\mathrm{N}$. Further, the MRR values during SC turning are higher than those during dry turning, for the same levels of $\mathrm{d}$, $\mathrm{f}$ and $\mathrm{N}$. So, it is clearly evident that turning in SC environment produces better surface quality than that of dry environment. It may be due to the fact that the water particles are finely atomized in presence of compressed air while passing through the nozzle. It eliminates the problem of flush out of the partially de-bonded particles from the machined surface of composites, which is a common problem in wet machining (Kannan \& Kishawy, 2006; Kannan \& Kishawy, 2008). Moreover, due to cooling effect produced in the air-water spray environment, the temperature of the cutting tool reduces, thus by enhancing the tool life.

\section{Table 6}

Experimental results and data processing of performance characteristics during turning in SC environment

\begin{tabular}{ccccccccccc}
\hline \multirow{2}{*}{ Run no. } & \multicolumn{3}{c}{ Machining process parameters } & \multicolumn{3}{c}{ Experimental results } & \multicolumn{3}{c}{ Normalized data } \\
& $\mathrm{d}$ & $\mathrm{f}$ & $\mathrm{N}$ & $\mathrm{Pa}$ & $\mathrm{Ra}$ & $\mathrm{T}$ & $\mathrm{MRR}$ & $\mathrm{Ra}$ & $\mathrm{T}$ & MRR \\
\hline Ideal sequence & & & & & & & & 1 & 1 & 1 \\
1 & 1 & 1 & 1 & 1 & 0.80 & 32.3 & 4.38 & 0.9670 & 1.0000 & 0.0000 \\
2 & 1 & 2 & 2 & 2 & 1.18 & 34.4 & 29.96 & 0.7582 & 0.7162 & 0.1928 \\
3 & 1 & 3 & 3 & 3 & 1.08 & 36.6 & 56.62 & 0.8132 & 0.4189 & 0.3938 \\
4 & 1 & 4 & 4 & 4 & 1.60 & 39.7 & 133.6 & 0.5275 & 0.0000 & 0.9741 \\
5 & 2 & 1 & 2 & 3 & 0.74 & 33.4 & 8.39 & 1.0000 & 0.8514 & 0.0302 \\
6 & 2 & 2 & 1 & 4 & 0.76 & 34.3 & 15.38 & 0.9890 & 0.7297 & 0.0829 \\
7 & 2 & 3 & 4 & 1 & 0.94 & 36.5 & 53.77 & 0.8901 & 0.4324 & 0.3723 \\
8 & 2 & 4 & 3 & 2 & 1.58 & 35.8 & 56.66 & 0.5385 & 0.5270 & 0.3941 \\
9 & 3 & 1 & 3 & 4 & 0.74 & 35 & 36.81 & 1.0000 & 0.6351 & 0.2445 \\
10 & 3 & 2 & 4 & 3 & 1.22 & 38.2 & 137.04 & 0.7363 & 0.2027 & 1.0000 \\
11 & 3 & 3 & 1 & 2 & 1.44 & 34.5 & 63.64 & 0.6154 & 0.7027 & 0.4467 \\
12 & 3 & 4 & 2 & 1 & 2.32 & 34.8 & 62.34 & 0.1319 & 0.6622 & 0.4369 \\
13 & 4 & 1 & 4 & 2 & 0.96 & 37.4 & 132.92 & 0.8791 & 0.3108 & 0.9689 \\
14 & 4 & 2 & 3 & 1 & 1.38 & 34.1 & 94.45 & 0.6484 & 0.7568 & 0.6790 \\
15 & 4 & 3 & 2 & 4 & 1.20 & 36.5 & 79.91 & 0.7473 & 0.4324 & 0.5694 \\
16 & 4 & 4 & 1 & 3 & 2.56 & 35.5 & 102.19 & 0.0000 & 0.5676 & 0.7373 \\
\hline
\end{tabular}

Deviation coefficients and grey relational coefficients with $\zeta=0.5$ are presented in Table 7 and Table 8 for dry turning and SC turning respectively.

Table 7

Deviation coefficients and grey relational coefficients during turning in dry environment

\begin{tabular}{ccccccc}
\hline Run no. & \multicolumn{3}{c}{ Deviation Coefficient } & \multicolumn{3}{c}{ Grey Relational coefficient } \\
& Ra & $\mathrm{T}$ & $\mathrm{MRR}$ & $\mathrm{Ra}$ & $\mathrm{T}$ & MRR \\
\hline Ideal sequence & & & & 1 & 1 & 1 \\
1 & 0.0000 & 0.0000 & 1.0000 & 1.0000 & 1.0000 & 0.3333 \\
2 & 0.2321 & 0.1765 & 0.9279 & 0.6830 & 0.7391 & 0.3502 \\
3 & 0.4515 & 0.3351 & 0.7803 & 0.5255 & 0.5987 & 0.3905 \\
4 & 0.2068 & 0.5633 & 0.5273 & 0.7075 & 0.4702 & 0.4867 \\
5 & 0.2068 & 0.2086 & 0.9118 & 0.7075 & 0.7057 & 0.3542 \\
6 & 0.6371 & 0.2656 & 0.8663 & 0.4397 & 0.6531 & 0.3660 \\
7 & 0.2278 & 0.9608 & 0.1824 & 0.6870 & 0.3423 & 0.7327 \\
8 & 0.6329 & 0.7415 & 0.4145 & 0.4413 & 0.4027 & 0.5468 \\
9 & 0.0970 & 0.5668 & 0.6265 & 0.8375 & 0.4687 & 0.4438 \\
10 & 0.2616 & 0.7291 & 0.3446 & 0.6565 & 0.4068 & 0.5920 \\
11 & 0.8797 & 0.3832 & 0.7886 & 0.3624 & 0.5661 & 0.3880 \\
12 & 0.7553 & 0.7041 & 0.3290 & 0.3983 & 0.4152 & 0.6032 \\
13 & 0.2468 & 1.0000 & 0.0000 & 0.6695 & 0.3333 & 1.0000 \\
14 & 0.4768 & 0.5365 & 0.3660 & 0.5119 & 0.4824 & 0.5774 \\
15 & 0.5781 & 0.3797 & 0.5651 & 0.4638 & 0.5684 & 0.4694 \\
16 & 1.0000 & 0.5668 & 0.6112 & 0.3333 & 0.4687 & 0.4499 \\
\hline
\end{tabular}


Table 8

Deviation coefficients and grey relational coefficients during turning in SC environment

\begin{tabular}{|c|c|c|c|c|c|c|}
\hline \multirow{2}{*}{ Run no. } & \multicolumn{3}{|c|}{ Deviation Coefficient } & \multicolumn{3}{|c|}{ Grey Relational coefficient } \\
\hline & $\mathrm{Ra}$ & $\mathrm{T}$ & MRR & $\mathrm{Ra}$ & $\mathrm{T}$ & MRR \\
\hline Ideal sequence & & & & 1 & 1 & 1 \\
\hline 1 & 0.0330 & 0.0000 & 1.0000 & 0.9381 & 1.0000 & 0.3333 \\
\hline 2 & 0.2418 & 0.2838 & 0.8072 & 0.6741 & 0.6379 & 0.3825 \\
\hline 3 & 0.1868 & 0.5811 & 0.6062 & 0.7280 & 0.4625 & 0.4520 \\
\hline 4 & 0.4725 & 1.0000 & 0.0259 & 0.5141 & 0.3333 & 0.9507 \\
\hline 5 & 0.0000 & 0.1486 & 0.9698 & 1.0000 & 0.7708 & 0.3402 \\
\hline 6 & 0.0110 & 0.2703 & 0.9171 & 0.9785 & 0.6491 & 0.3528 \\
\hline 7 & 0.1099 & 0.5676 & 0.6277 & 0.8198 & 0.4684 & 0.4434 \\
\hline 8 & 0.4615 & 0.4730 & 0.6059 & 0.5200 & 0.5139 & 0.4521 \\
\hline 9 & 0.0000 & 0.3649 & 0.7555 & 1.0000 & 0.5781 & 0.3982 \\
\hline 10 & 0.2637 & 0.7973 & 0.0000 & 0.6547 & 0.3854 & 1.0000 \\
\hline 11 & 0.3846 & 0.2973 & 0.5533 & 0.5652 & 0.6271 & 0.4747 \\
\hline 12 & 0.8681 & 0.3378 & 0.5631 & 0.3655 & 0.5968 & 0.4703 \\
\hline 13 & 0.1209 & 0.6892 & 0.0311 & 0.8053 & 0.4205 & 0.9415 \\
\hline 14 & 0.3516 & 0.2432 & 0.3210 & 0.5871 & 0.6727 & 0.6090 \\
\hline 15 & 0.2527 & 0.5676 & 0.4306 & 0.6642 & 0.4684 & 0.5373 \\
\hline 16 & 1.0000 & 0.4324 & 0.2627 & 0.3333 & 0.5362 & 0.6556 \\
\hline
\end{tabular}

Table 9 represents grey relational grades and their order for the multiple performance characteristics for turning in dry environment; and those for turning in SC environment are presented in Table 10.

\section{Table 9}

Grey relational grades and their order during turning in dry environment

\begin{tabular}{ccc}
\hline Run no. & Grey relational grade & Order \\
\hline 1 & 0.7778 & 1 \\
2 & 0.5908 & 3 \\
3 & 0.5049 & 10 \\
4 & 0.5548 & 7 \\
5 & 0.5891 & 4 \\
6 & 0.4862 & 12 \\
7 & 0.5873 & 5 \\
8 & 0.4636 & 14 \\
9 & 0.5833 & 6 \\
10 & 0.5518 & 8 \\
11 & 0.4388 & 15 \\
12 & 0.4722 & 13 \\
13 & 0.6676 & 2 \\
14 & 0.5239 & 9 \\
15 & 0.5005 & 11 \\
16 & 0.4173 & 16 \\
\hline
\end{tabular}

Table 10

Grey relational grades and their order during turning in SC environment

\begin{tabular}{ccc}
\hline Run no. & Grey & Order \\
\hline 1 & 0.7572 & 1 \\
2 & 0.5648 & 10 \\
3 & 0.5475 & 13 \\
4 & 0.5994 & 8 \\
5 & 0.7037 & 3 \\
6 & 0.6602 & 5 \\
7 & 0.5772 & 9 \\
8 & 0.4953 & 15 \\
9 & 0.6588 & 6 \\
10 & 0.6800 & 4 \\
11 & 0.5557 & 12 \\
12 & 0.4775 & 16 \\
13 & 0.7224 & 2 \\
14 & 0.6229 & 7 \\
15 & 0.5566 & 11 \\
16 & 0.5084 & 14 \\
\hline
\end{tabular}

Response tables were generated using Taguchi method to calculate the mean grey relational grade for each factor level, as illustrated in Table 11 for turning in dry environment and in Table 12 for turning in SC environment.

\section{Table 11}

Response table for means of grey relational grade during turning in dry environment

\begin{tabular}{|c|c|c|c|c|c|c|}
\hline \multirow{2}{*}{$\begin{array}{c}\text { Process } \\
\text { parameters }\end{array}$} & \multicolumn{4}{|c|}{ Grey relational grade } & \multirow{2}{*}{ Max-min } & \multirow{2}{*}{ Rank } \\
\hline & Level 1 & Level 2 & Level 3 & Level 4 & & \\
\hline $\mathrm{d}$ & 0.6071 & 0.5315 & 0.5115 & 0.5273 & 0.0955 & 2 \\
\hline $\mathrm{f}$ & 0.6544 & 0.5382 & 0.5079 & 0.4770 & 0.1775 & 1 \\
\hline $\mathrm{N}$ & 0.5300 & 0.5381 & 0.5189 & 0.5904 & 0.0714 & 3 \\
\hline
\end{tabular}


Table 12

Response table for means of grey relational grade during turning in SC environment

\begin{tabular}{|c|c|c|c|c|c|c|}
\hline \multirow{2}{*}{$\begin{array}{c}\text { Process } \\
\text { parameters }\end{array}$} & \multicolumn{4}{|c|}{ Grey relational grade } & \multirow{2}{*}{ Max-min } & \multirow{2}{*}{ Rank } \\
\hline & Level 1 & Level 2 & Level 3 & Level 4 & & \\
\hline $\mathrm{D}$ & 0.6172 & 0.6091 & 0.5930 & 0.6026 & 0.0242 & 4 \\
\hline $\mathrm{F}$ & 0.7105 & 0.6320 & 0.5592 & 0.5201 & 0.1904 & 1 \\
\hline $\mathrm{N}$ & 0.6204 & 0.5756 & 0.5811 & 0.6447 & 0.0691 & 2 \\
\hline $\mathrm{Pa}$ & 0.6087 & 0.5845 & 0.6010 & 0.6187 & 0.0342 & 3 \\
\hline
\end{tabular}

Total mean grey relational grade $=0.6055$

In Table 11 the largest values of grey relational grade are obtained for the combination of d1-f1-N4, which indicates that the optimal combination of machining process parameters for the multiple performance characteristics during dry turning of the composite is depth of cut of $0.2 \mathrm{~mm}$, feed of 0.04 $\mathrm{mm} / \mathrm{rev}$ and spindle speed of $930 \mathrm{rpm}$. Similarly, in Table 12 the largest values of grey relational grade are obtained for the combination of d1-f1-N4-Pa4, indicating a depth of cut of $0.2 \mathrm{~mm}$, feed of 0.04 $\mathrm{mm} / \mathrm{rev}$, spindle speed of $930 \mathrm{rpm}$ and air pressure of $1.5 \mathrm{bar}$ (at $\mathrm{Pw}=3 \mathrm{bar}$ ) is the optimal parameter combination for the multiple performance characteristics during turning the composite in SC condition. The main effect plots for means of grey relational grade are shown in Figure 6 and Figure 7 for dry turning and spray cooled turning of the composite respectively. The dashed lines in the main effect plots represent the total mean of the grey relational grade.

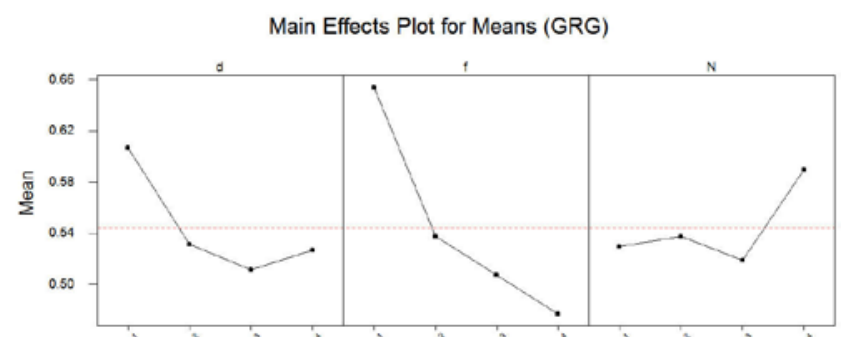

Fig. 6. Main effect plots for means of grey relational grade during turning in dry environment

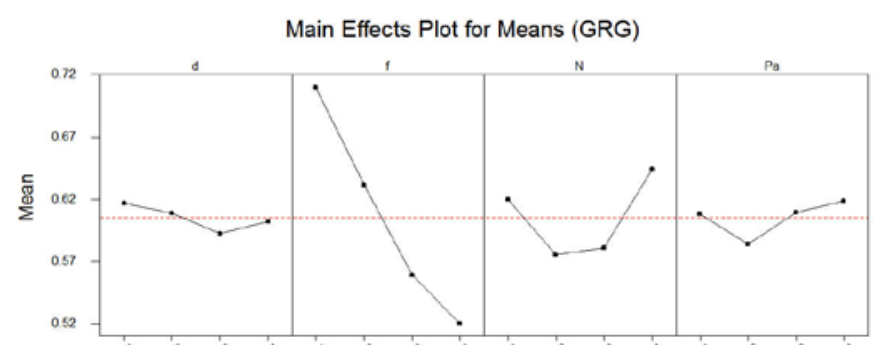

Fig. 7. Main effect plots for means of grey relational grade during turning in SC environment

\subsection{Analysis of variance (ANOVA) for Grey relational grade}

In order to investigate the significance of machining process parameters on the multiple performance characteristics, ANOVA was conducted for grey relational grade at $95 \%$ confidence level using MINITAB software. Total sum of squared deviations (SST) can be calculated using Eq. (7).

$$
S S_{T}=\sum_{j=1}^{p}\left(\gamma_{j}-\gamma_{m}\right)^{2},
$$

where $\mathrm{p}=$ number of experiments in the orthogonal array, $\gamma_{j}=$ mean of grey relational grade for $\mathrm{j}^{\text {th }}$ experiment and $\gamma_{m}=$ total mean of grey relational grade. ${ }^{16}$ Mean square (MS) can be obtained by dividing sum of squared deviations (SS) by the corresponding degree of freedom (DF), i.e.

$$
M S=\frac{S S}{D F}
$$

Fisher's value (F) and probability of significance (P) can be used to determine the significance of machining process parameters on the multiple performance characteristics. For a large value of $\mathrm{F}$ or small value of $\mathrm{P}$ the corresponding machining parameter has a significant effect on the performance characteristics. Percentage of contribution of a machining parameter can be calculated by dividing $\mathrm{SS}_{\mathrm{T}}$ by the corresponding SS, as presented in Eq. (9). 
$\%$ of contribution $=\frac{S S_{T}}{S S} \times 100$

Table 13 and Table 14 represent the ANOVA results for grey relational grade in dry and SC turning environments respectively. From the ANOVA tables it is observed that feed is the only significant machining process parameter for Ra, T and MRR considered simultaneously, during turning both in dry and SC environments. Percentage of contribution of feed for the multi-response characteristics is 58.33 for dry turning environment and that for SC turning environment is 79.29.

Table 13

ANOVA results for grey relational grade during turning in dry environment

\begin{tabular}{ccccccc}
\hline Process & Degree of & Sum of squares & Mean square & F & P & Contribution (\%) \\
\hline $\mathrm{d}$ & 3 & 0.0218 & 0.0072 & 2.48 & 0.159 & 17.64 \\
$\mathrm{f}$ & 3 & 0.0721 & 0.0240 & 8.17 & 0.015 & 58.33 \\
$\mathrm{~N}$ & 3 & 0.0120 & 0.0040 & 1.36 & 0.341 & 9.71 \\
Error & 6 & 0.0176 & 0.0029 & & & 14.24 \\
\hline Total & 15 & 0.1236 & & & & 100.00 \\
\hline
\end{tabular}

\section{Table 14}

ANOVA results for grey relational grade during turning in SC environment

\begin{tabular}{ccccccc}
\hline Process & Degree of & Sum of & Mean square & F & P & Contribution \\
\hline $\mathrm{d}$ & 3 & 0.0013 & 0.0004 & 0.24 & 0.864 & 1.22 \\
$\mathrm{f}$ & 3 & 0.0846 & 0.0282 & 16.12 & 0.024 & 79.29 \\
$\mathrm{~N}$ & 3 & 0.0130 & 0.0043 & 2.47 & 0.238 & 12.18 \\
$\mathrm{~Pa}$ & 3 & 0.0026 & 0.0008 & 0.49 & 0.713 & 2.44 \\
Error & 3 & 0.0052 & 0.0017 & & & 4.87 \\
\hline Total & 15 & 0.1067 & & & & 100.00 \\
\hline
\end{tabular}

\subsection{Verification of optimal machining process parameters through confirmation experiment}

After finding the optimal combination of machining process parameters and the most influencing factor for Ra, $\mathrm{T}$ and MRR, the final step is to verify for the responses by conducting some confirmation experiments. Table 15 and Table 16 show the results of the confirmation experiments during turning the composite in dry and SC environments respectively.

\section{Table 15}

Results of cutting performance using the initial and optimal process parameters during turning in dry environment

\begin{tabular}{cccc}
\hline & Initial process parameters & \multicolumn{2}{c}{ Optimal process parameters } \\
\cline { 3 - 4 } & & Prediction & Experiment \\
\hline Level & d2-f2-N2 & d1-f1-N4 & d1-f1-N4 \\
Ra & 2.68 & & 0.72 \\
T & 54.62 & 32.7 \\
MRR & 20.22 & 86.45 \\
Grey relational grade & 0.5158 & 0.7631 & 0.9407 \\
\hline
\end{tabular}

\section{Table 16}

Results of cutting performance using the initial and optimal process parameters during turning in SC environment

\begin{tabular}{cccc}
\hline & \multirow{2}{*}{ Initial process parameters } & \multicolumn{2}{c}{ Optimal process parameters } \\
\cline { 3 - 4 } & & Prediction & Experiment \\
\hline Level & d2-f2-N2-Pa2 & d1-f1-N4-Pa4 & 0.66 \\
Ra & 1.18 & & 32.00 \\
$\mathrm{~T}$ & 36.02 & & 129.22 \\
MRR & 35.24 & 0.7748 & 0.9635 \\
\hline
\end{tabular}


In both the cases the values of Ra and $\mathrm{T}$ for optimal combination of process parameters were sufficiently lower as compared to those of initial process parameters. However, the MRR for optimal combination of process parameters was sufficiently higher than that of initial process parameters for both the cases. The improvements in grey relational grade for optimal parametric combination than that for initial process parameters are 0.4250 and 0.4412 for turning in dry and SC environments respectively. Further it is observed that for optimal process parameters the experimental values of $\mathrm{Ra}$ and $\mathrm{T}$ in case of turning in SC environment are lower and MRR is higher than those values in dry turning.

\section{Conclusion}

1. Turning SiC reinforced AMCs in spray cooled environment produces better surface quality, reduced cutting tool temperature and improved productivity as compared to dry turning.

2. From the response table, the largest values of the grey relational grade are achieved for the depth of cut of $0.2 \mathrm{~mm}$, feed of $0.04 \mathrm{~mm} / \mathrm{rev}$ and spindle speed of $930 \mathrm{rpm}$ for dry turning of the composite. It is the recommended levels of cutting parameters for turning SiC reinforced AMCs in dry environment for minimizing average surface roughness, minimizing cutting tool temperature and maximizing the material removal rate, simultaneously considered. Similarly, during turning in SC environment, the largest values of the grey relational grade are obtained for the depth of cut of $0.2 \mathrm{~mm}$, feed of $0.04 \mathrm{~mm} / \mathrm{rev}$, spindle speed of $930 \mathrm{rpm}$ and air pressure of 1.5 bar (at water pressure of $3 \mathrm{bar}$ ). It is the recommended levels of cutting parameters for turning the composites in SC environment for the multi-response characteristics (Ra, T, and MRR).

3. ANOVA results for grey relational grade indicates that feed is the only significant machining process parameter for the multi-response characteristics under consideration, for both the dry and SC environments. The contribution of feed in SC environment is quite large as compared to that in dry environment.

4. Confirmation experiments reveal that the improvement in grey relational grade of optimal combination of parameters than the initial setting of parameters is 0.4250 for dry turning and 0.4412 for spray cooled turning of the composite.

\section{Acknowledgement}

Support of this work under DST/MERC, Govt of India, New Delhi core research funding is gratefully acknowledged. The authors also acknowledge the assistance of the Department of Science and Technology (DST), Govt of India, New Delhi and KIIT University, India for the composite fabrication and machining equipment.

\section{References}

Chandrasekaran, M. \& Tamang, S. (2014). Desirability analysis and genetic algorithm approaches to optimize single and multi response characteristics in machining Al-SiCp MMC, 5th International \& 26th All India Manufacturing Technology, Design and Research Conference, 653.1-653.6.

Ciftci, I, Turker, M \& Seker, U. (2004). Evaluation of tool wear when machining SiCp -reinforced Al2014 alloy matrix composites. Materials and Design, 25, 251-255.

Das, D.K., Mishra, P.C., \& Singh, S. (2014). Properties of ceramic-reinforced aluminum matrix composites - a review. International Journal of Mechanical and Materials Engineering, 9, 1-16.

Ding, X., Liew W.Y.H. \& Liu, X.D. (2005). Evaluation of machining performance MMC with PCBN and PCD tools, Wear, 259, 1225-1234.

Gallab, M.E.I. \& Sklad, M. (1998). Machining of Al/SiC particulate metal-matrix composites, Part-II: workpiece surface integrity. Journal of Materials Processing Technology, 83, 277-285.

Gupta, M. \& Kumar, S. (2013). Multi-objective optimization of cutting parameters in turning using grey relational analysis. International Journal of Industrial Engineering Computations, 4, 547-558. 
Hung, N.P., Boey, F.Y.C, \& Khor, K.A. (1995). Machinability of cast and powder-formed aluminum alloys reinforced with SiC particles. Journal of Material Processing Technology, 48, 291-297.

Kannan, S. \& Kishawy, H.A. (2008). Tribological aspects of machining aluminum metal matrix composites, Journal of Materials Processing Technology, 198, 399-406.

Kannan, S. \& Kishawy, H.A. (2006).Surface characteristics of machined aluminum metal matrix composites. International Journal of Machine Tools \& Manufacture, 46, 2017-2025.

Kilickap, E., Cakir, O., \& Aksoy, M. (2005). Study of tool wear and surface roughness in machining of homogenized SiC-p reinforced aluminum metal matrix composite. Journal of Materials Processing Technology, 164-165, 862-867.

Krishna, A.A.S.R. \& Reddy, P.R. (2012). Temperature Prediction in Orthogonal Machining of A1/SiCp Composites, International Journal of Emerging Technology and Advanced Engineering, 2(6), 223229.

Krishnamurthy, K. \& Venkatesh, J. (2013). Assessment of surface roughness and material removal rate on machining of $\mathrm{TIB}_{2}$ reinforced aluminum 6063 composites: a Taguchi's approach. International Journal of Scientific and Research Publications, 3(1), 1-6.

Kumar, G.B.V., Rao, C.S.P, \& Selvaraj, N. (2010). Studies on Al6061-SiC and Al7075- $\mathrm{Al}_{2} \mathrm{O}_{3}$ metal matrix composites. Journal of Minerals \& Materials Characterization \& Engineering, 9 (1), 43-55.

Lin, C.L. (2004). Use of Taguchi method and grey relational analysis to optimize turning operations in multiple performance characteristics. Materials and Manufacturing Processes, 19 (2), 209-220.

Manna, A. \& Bhattacharyya, B. (2002). A study on different tooling system during machining of Al/SiC MMC. Journal of Materials Processing Technology, 123, 476-482.

Radhika, N., Subramanian, R. \& Sajith, A. (2014). Analysis of chip formation in machining aluminum hybrid composites. E3 Journal of Scientific Research, 2(1), 009-015.

Schubert, A. \& Nestler, A. (2011). Enhancement of surface integrity in turning of particle reinforced aluminum matrix composites by tool design. 1st CIRP Conference on Surface Integrity (CSI), Procedia Engineering, 19, 300-305.

Sreenivasulu, R. \& Rao, C.S. (2012). Application of grey relational analysis for surface roughness and roundness error in drilling of Al 6061 alloy, International Journal of Lean Thinking, 3(2), 67-78.

Suryanarayanan, K., Praveen, R. \& Raghuraman, S. (2013). Silicon carbide reinforced aluminum metal matrix composites for aerospace applications: a literature review. International Journal of Innovative Research in Science, Engineering and Technology, 2(11), 6336-6344.

Tzeng, C.J, Lin, Y.H, \& Yang, Y.K. (2009). Optimization of turning operations with multiple performance characteristics using the Taguchi method and Grey relational analysis. Journal of Materials Processing Technology, 209, 2753-2759. 